\section{Birlesik Dünya Arastırma New Trends and Issues BD-CENTER Proceedings on Humanities and Innovasyon ve Yayıneılık Merkezi \\ Social Sciences}

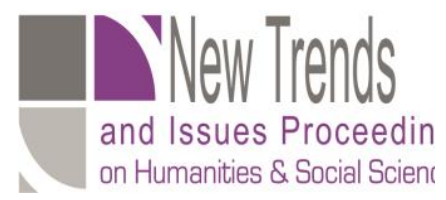

Volume 7, Issue 3, (2020) 160-168

www.prosoc.eu

Selected Paper of 9th Cyprus International Conference on Educational Research (CYICER-2020) 18-20 June 2020, Bahçeşehir Cyprus University Nicosia / TRNC (ONLINE CONFERENCE)

\title{
Examining the role of virtual reality and augmented reality technologies in education
}

Bekim Fetaji*, Department of Informatics, Mother Teresa University, MK, Mirche Acev No.4, 1000 Skopje, North Macedonia https://orcid.org/0000-0001-9578-9443

Majlinda Fetaji, Department of Computer Sciences, South East European University, Ilindenska 335, 1200 Tetovo, North Macedonia https://orcid.org/0000-0001-9552-9043

Özcan Ozcan Asilkan, Department of Computer Engineering, Metropolitan University of Tirana, Rruga Pjeter Budi, 1000 Tirane AL, Albania https://orcid.org/0000-0001-8220-2332

Mirlinda Ebibi, Department of Computer Sciences, South East European University, Ilindenska 335, 1200 Tetovo, North Macedonia

\section{Suggested Citation:}

Fetaji, B., Fetaji, M., Asilkan, O. \& Ebibi, M. (2020). Examining the role of virtual reality and augmented reality technologies in education. New Trends and Issues Proceedings on Humanities and Social Sciences. 7(3), pp 160-168.Available from: $\underline{\text { www.prosoc.eu }}$

Received fromAugust 12, 2020; revised from September 12, 2020; accepted from November 12, 2020.

Selection and peer review under responsibility of Prof. Dr. Huseyin Uzunboylu, Higher Education Planning, Supervision, Accreditation and Coordination Board, Cyprus.

${ }^{\circ} 2020$ Birlesik Dunya Yenilik Arastirmave Yayincilik Merkezi. All rights reserved.

\begin{abstract}
In the last decade, applications of virtual reality (VR) and augmented reality (AR) technologies have rapidly increased. Although they are used especially in the game industry, their importance in education has also becoming more evident. As there are not enough academic researches on this field, we aimed to examine the role of VR and AR technologies in education. During the study, the implementation of VR and AR applications in education was analysed as well as impact factors, barriers and levels of knowledge transfer were investigated. We propose an approach to address the various identified issues. This study aims to contribute to the field with the comparison of the results, followed by analyses and recommendations for future work.
\end{abstract}

Keywords: Virtual reality, augmented reality, education, learning models, assessment, flipped learning.

\footnotetext{
* ADDRESS FOR CORRESPONDENCE: Majlinda Fetaji, Department of Computer Sciences, South East European University, Ilindenska 335, 1200 Tetovo, North Macedonia

E-mail address: $\underline{\text { m.fetaji@seeu.edu.mk }}$
} 


\section{Introduction}

The advances in high technologies brought about two novel applications in the last decade: virtual reality (VR) and augmented reality (AR) technologies. VR contributed to the generation of realistic images, sounds and other sensations that take people into a spectacular imaginary world. AR added virtual stuff to the real-world environment and contributed to the buzz. In this study, possible outcomes of VR and AR have been particularly investigated and tested. Because of the complexities and high costs of VR/AR gadgets and other various difficulties, these innovations have not discovered their way into the business world so far (Billingsley, Smith, Smith \& Meritt, 2019). Enlarged and computer-generated reality may offer various opportunities and benefits; however, currently they are conveyed the same way.

Over the last 10years, smart phones hit the market and have made their screens one of the fundamental elements of our lives. Subsequently, they changed how we convey, work, travel, buy and so on. However, when the developers of AR used it on Pokemon Go, no one had previously used AR in such a manner on mobile devices. Pokemon Go effectively used the approved new way of interaction that AR offered with increased reality. Since the Pokemon Go's first use in 2016, new smart phone implementations of AR have been used.

There is still a lack of satisfactory research on VR and AR, especially from the perspective of online education. This research study was conducted in order to investigate the possible outcomes of them by creating a proper online learning content.

\section{Literature review}

This study aims to make contributions to the field by examining the role of VR technologies and their applications in education. It reviews the examination audits past proposition as discussed by Diao and Shih (2019) and explains some expressed misinterpretations. Although definitions exist for VR and $A R$, they are not always explained or defined in the same manner or sometimes addressed together as AVR-augmented VR (Ibanez \& Delgado-Kloos, 2018). In its least difficult structure, the 3D VR recreation can run on a standard personal computer screen. A straight forward, yet amazing work area-based VR condition impart shows that complex frameworks are not generally expected to accomplish a specific objective. Further developed and vivid acknowledge of VR incorporates alleged cavern frameworks, where the virtual world is anticipated around the client with information projectors, and now ubiquitous head-mounted presentations as discussed by Lim et al. (2018). Rather than VR, where the entire condition is reproduced, AR recreates just pieces of it and incorporates these virtual components consistently with the genuine condition of a client, therefore for all intents and purposes 'increasing' it (Gavilanes, Abasolo \& Cuji, 2018).

\subsection{Literature review VR/AR in education}

From the examinations that specified an educational methodology or instructional procedure, intelligent and arranged learning were fundamentally referenced (Bonner \& Reinders, 2018). Both allude to the computer-generated experience and expanded reality used in the development of virtual information through non-stop cooperation with the earth and in real-life circumstances. In any case, the term was rarely characterised and the examination concentrated on e-marking without tending to the absence of representation, inundation or intuitiveness that for the most part characterises VR (Diao \& Shih, 2019). With an anticipated innovative turn of events and as more exploration centres on the explicit aspects of VR or AR, both have started to be defined together because of the beginning idea of examination in VR and AR; considerations had utilised the terms virtual condition, AR and virtual universes conflictingly and frequently, without including meanings of the terms, for instance, Billingsleyet al. (2019)referred to computer-generated reality and all kinds of virtualisations. 
Less significantly, other educational methodologies referenced incorporate community-oriented learning and game-based learning. Collective learning is fundamentally portrayed when learning exercises are intended to be explained in gatherings or groups. Along these lines, students use AR to build up the movement and simultaneously partake in groups or gatherings (e.g., Gadelha, 2018). For instance, Jaramillo Henao et al. (2018) built a game in which students, with the utilisation of an AR application, could tackle difficulties in a gamification mode to find out about food science. One of the principle challenges when testing the AR devices were the troubles students experience when utilising AR (i.e., ease of use, application-related and specialised issues), which may increase the time required for learning and the psychological heap of the students, hampering their inspiration and execution (Diao \& Shih, 2019). According to Godwin-Jones (2016),gaming remained the segment expected to draw in the most AR/VR-related ventures throughout the following year; however, its driving position dropped a piece from the 2016 review (78\%) to the 2018 overview (59\%).

\section{Analysis of traditional versus flipped models}

This study aims to investigate the benefits and challenges of the flipped classroom where we incorporated the specifics of virtual technologies implication by devising a new instructional VR/AR flipped learning model and combined all that with VR and AR teaching for higher education students.

The traditional lecture-based classroom is defined as the one in which students attend lectures and acquire information latently from the teacher, during their classes and complete assignments after class. In the conventional study classroom model, the instructor remains between the students and the information. Students have no (or little) previous information about the subject when they come to class. In the class, they get all the essential information. The procedure of musings is generally observed during the tests.

Flipped study transverses the traditional learning experience. Talks are recorded outside of the class and later imparted to students to audit as their 'schoolwork'. Study hall time is saved for students to take part in conversations and exercises.

By making the learning content accessible on request, students can watch them at any time and place that meets their requirements. They can likewise audit significant or hazy subtleties as frequently varying until they are surely known. Accordingly, students come to class with a superior handle of the point and can take part in conversations and exercises that apply what they have realised. Homework exercises may incorporate gathering works, considering tests, introductions and different utilisations of the topic. As individual inquiries emerge, the educator and individual students can react by furnishing every understudy with a progressively customised learning experience.

Computer-generated reality/enlarged reality and the traditional talk-based study classroom versus flipped classroom were thought about as dependent on understudy and instructor input polls, understudy learning weight and scores on tests just as their consequences for the capacities of basic reasoning, logical exploration, dynamic learning and viable application. In the conventional model, the readings are done before class, instructing is done in class and assignments/schoolwork are done outside/after class. In the flipped study hall, the talks are done before class (recordings), assignments are finished during class and appraisals are done outside class by means of the utilisation of programming and online test instruments. 


\section{Traditional Model}

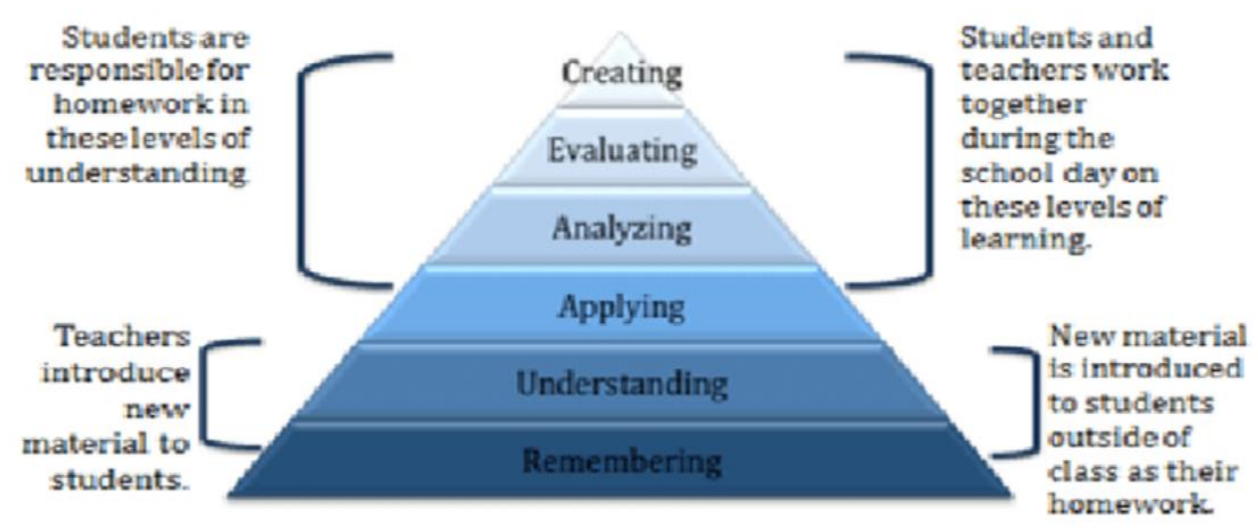

Figure 1. Comparison summary of traditional versus flipped model

\section{Research methodology}

We have investigated and reviewed the specifics of flipped learning, virtual learning and augmented learning issues and which is the best way to conceptually organise online lectures. Our hypothesis is as follows:

H1: Merging the flipped classroom with immersive 3D VR and AR will improve a student's ability to understand and level of knowledge transfer. In order to verify it, we have used a questionnaire and further identified the results. Our research questions are as follows:

1) What are the research gaps in VR and AR education research?

2) Which forms of VR and AR have drawn most of the attention in education research?

3) What methodologies/theories are being utilised to research VR and AR in education?

\section{Results}

During the study, differences between classical and flipped learning have been analysed at first, then possibilities of $V R, A R$ and their implementation in online education have been investigated. Through the case studies, several ways of the implementation of VR and AR have been investigated and combined with the flipped learning instructional model. Impact factors and the way students evaluate the learning process have been evaluated and compared with other classical lectures they have. Furthermore, we compared the results by using different methods and software. We used content with 'AVR Creator' for the course 'Computer Architecture', more specifically the Sound Card. 42 students from two groups were asked to complete a pre-test of eight questions. The first group served as the control group and they firstly took the lecture in the classical classroom. The second group of students went through with reading homework, practicing and setting up the environment of $V R / A R$ and solving exercises. After the classroom teaching, students from both groups were required to complete an anonymous questionnaire to assess their points of view of the module (eight items covering both positive and negative angles). Furthermore, subsequent to finishing the module, students were asked to self-assess their ability and enthusiasm for hardware engineering. Students' viewpoints and self-assessments were measured utilising a 5-point Likert-type scale. The results are shown in the following figures by referring to the survey questions. 
1) Select your gender?

31 responses

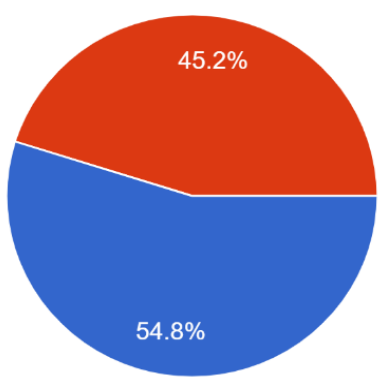

Female

Male

Figure 2. Comparison summary of traditional vs flipped classroom

Based on the gender detection, it seems that female students are more interested in studying computer technology fields.
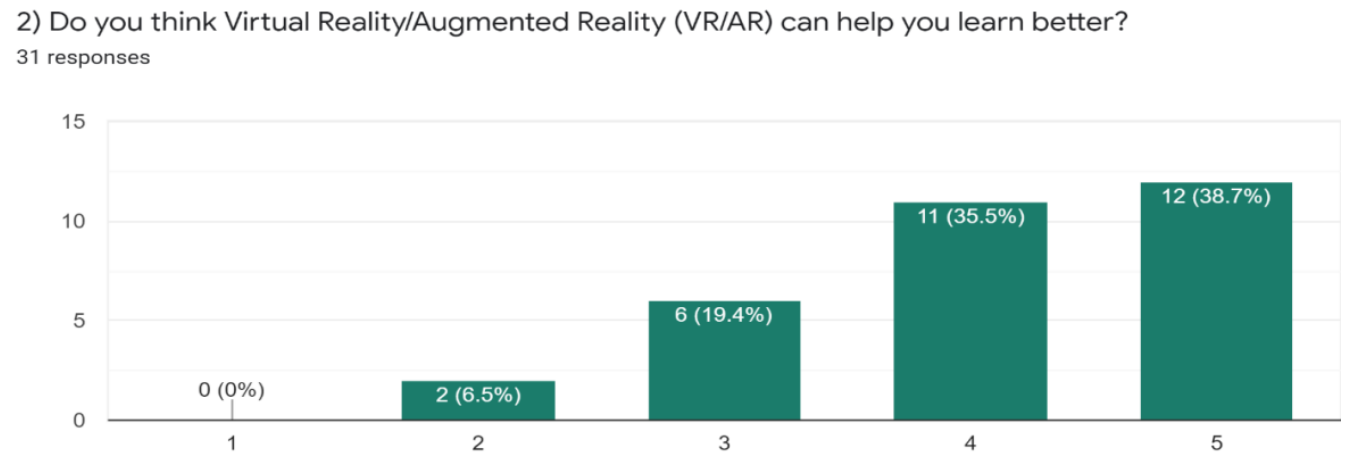

Figure 3. Comparison summary of 'Can VR/AR help to learn better?'

Majority of the respondents think that the VR/AR technology use in education helped them to learn better. We can see that $38.7 \%$ of users who have used the VR/AR system strongly agree, $35.5 \%$ agree, which makes in total $74.2 \%$ who consider that the VR/AR implementation helps them learn better. 3) The impact of VR/AR on increasing the attention and interest in the learning process is high?
31 responses

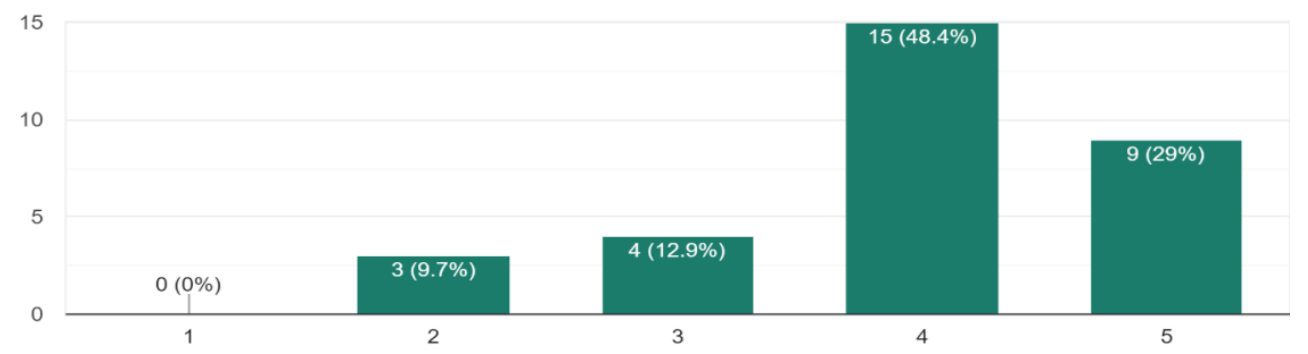

Figure 4. Increase in attention during the learning process

The results show that the majority of respondents (77.4\%) found that VR/AR technology use in education increased their attention during the learning process. We can see that $29 \%$ of the users who have used the VR/AR system strongly agree and $48.4 \%$ agree, which makes in total $77.4 \%$ who consider that the VR/AR implementation increased their attention significantly during the learning process. This indicates that their focus is quite higher than in the classical classroom. 
4) The impact of VR/AR on improving students success is high?
31 responses

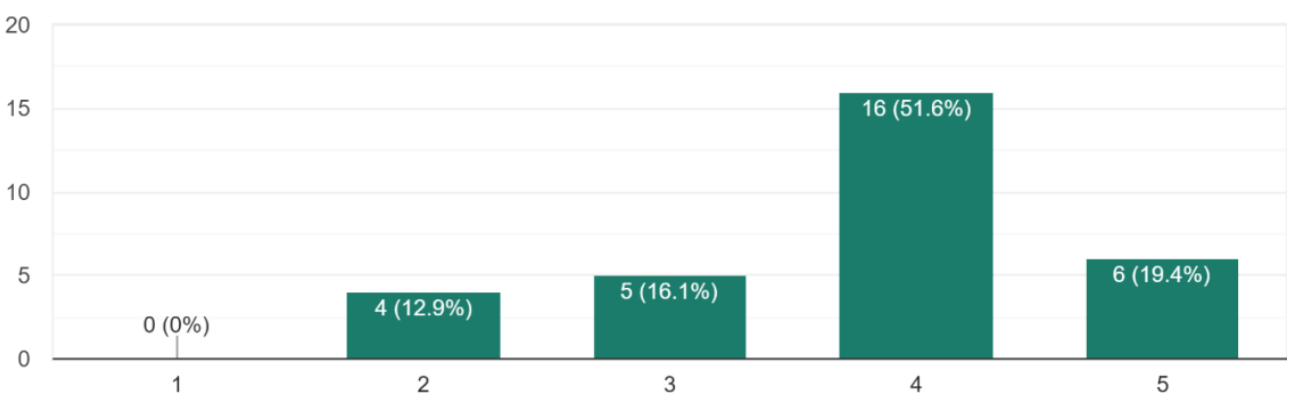

Figure 5. Impact of VR/AR on improving success

Majority of the respondents ( $71 \%$ in total) found that the VR/AR technology use in education helped improve their success at the end of the learning process. We can see that $19.4 \%$ of the users who have used the VR/AR system strongly agree and $51.6 \%$ agree, which makes in total $71 \%$ who consider that the VR/AR implementation increased their success after the learning process. This indicates that their success and achieved points are quite higher than in the classical classroom.

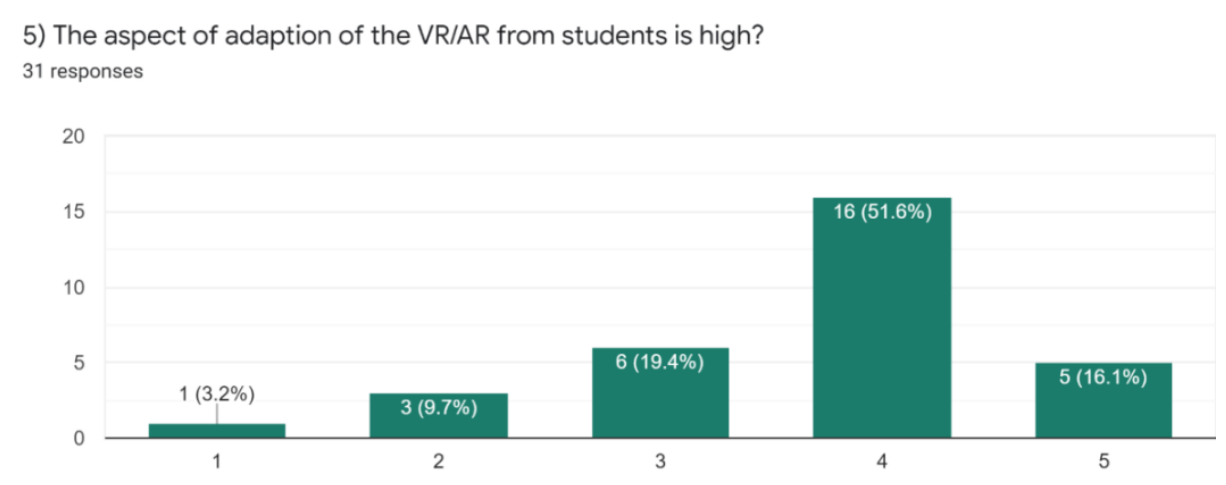

Figure 6. Adoption of the VR/AR technology

Majority of the respondents (67.7\% in total) found that the VR/AR technology use in education helped improve the adoption of these technologies by students during the learning process. We can see that $16.1 \%$ of users who have used the VR/AR system strongly agree and $51.6 \%$ agree, which makes in total $67.7 \%$ who consider that the VR/AR implementation will likely be adopted as the preferred way of instruction for learning by the students during the learning process. This indicates that they would more likely use this technology in learning than the way it was done in the classical classroom.

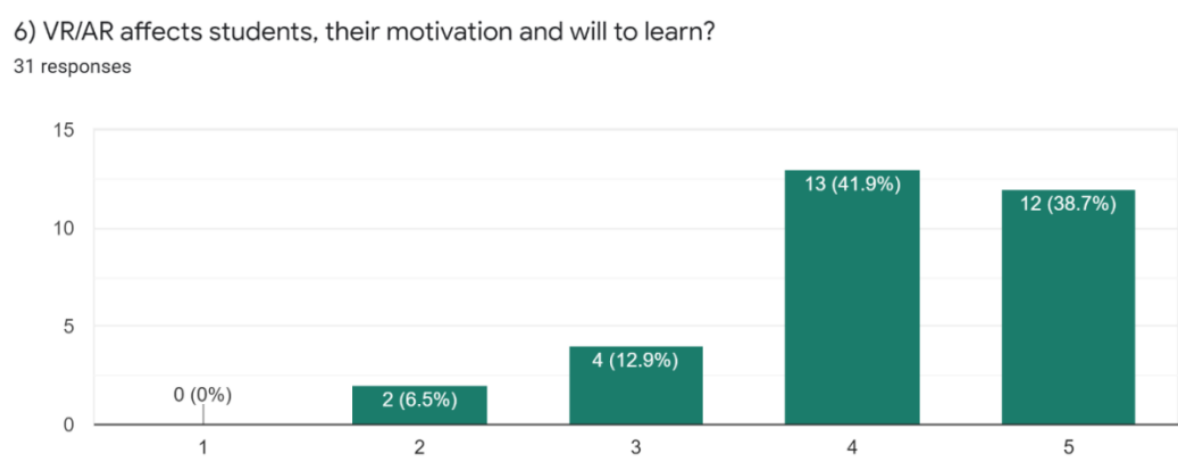

Figure 7. Impact of VR/AR on motivation and willingness 
Majority of the respondents (80.6\%) found that the VR/AR technology use in education improved their motivation and willingness to learn. We can see that $38.7 \%$ of the users who have used the VR/AR system strongly agree and $41.9 \%$ agree, which makes in total $80.6 \%$ who consider that the VR/AR implementation increased their willingness and motivation for learning. This indicates that they are more motivated when using this technology in learning than the way it was done in the classical classroom.
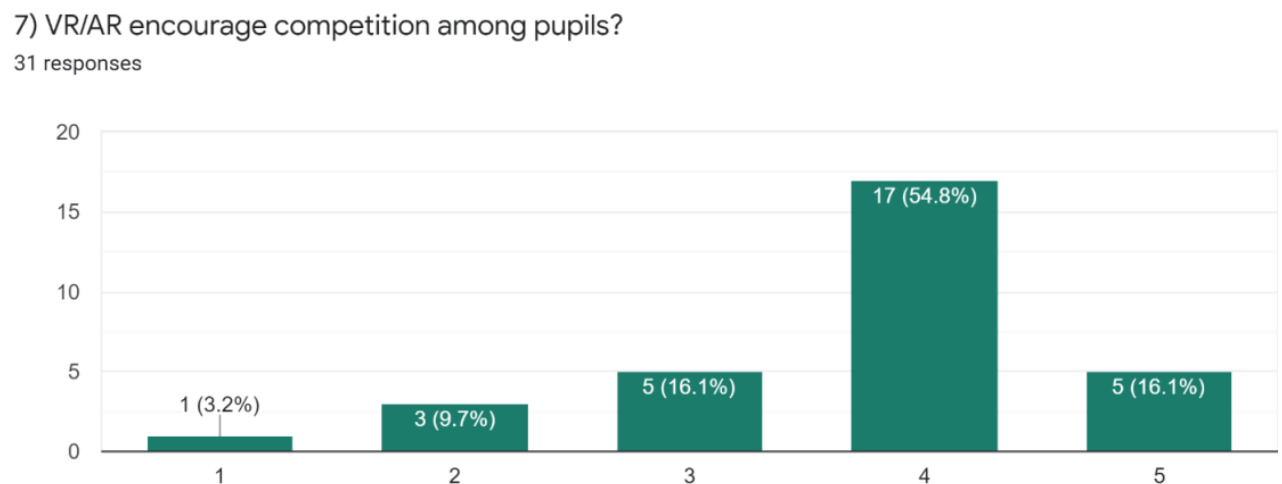

Figure 8. Impact on the encouragement of the competition

The majority of the respondents ( $70.9 \%$ in total) found that the VR/AR technology use in education helped increase the competition among students during the learning process. We can see that $16.1 \%$ of the users who have used the VR/AR system strongly agree and $54.8 \%$ agree, which makes in total $70.9 \%$ who consider that the VR/AR implementation increases the competition among students. We conclude that this indicates that the competition is encouraged and they would more likely use this technology and achieve higher results in learning than the way it was done in the classical classroom.

8 ) VR/AR have improved my thorough understanding of the course content?
31 responses

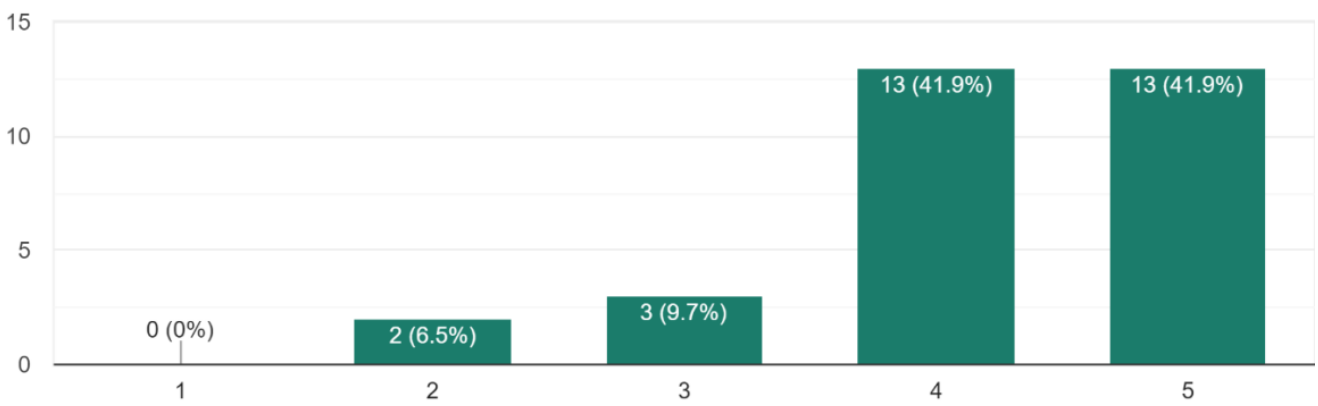

Figure 9. Improvement of thorough understanding

Majority of the respondents (83.8\%) found that the VR/AR technology helped them improve their thorough understanding during the learning process. We can see that $41.9 \%$ of the users who have used the VR/AR system strongly agree and $41.9 \%$ agree, which makes in total $83.8 \%$ who consider that the VR/AR implementation will likely increase their understanding and that this is the proper way of instruction for learning during the learning process. We conclude that this indicates an increase in their learning and knowledge and that they would more likely use this technology in learning than the way it was done in the classical classroom. 


\section{Conclusion}

This study started with the investigation of the specifics of traditional classroom and continued with an implementation with flipped classroom implementation in classical and online education. It concluded with the comparison of the results and analyses. During the study, we identified the different issues that are considered to be the impacting barriers in the implementation of VR and AR. We proposed an approach to address them by integrating flipped classroom with online education, and identified what constitutes a good online learning model that will enable a higher level of knowledge transfer and enhance the learning outcomes. The devised VR/AR flipped instructional method with instructors understudy collaborations may assist students with utilising their valuable time appropriately.

Based on the results, we note that the majority of the respondents from both groups are highly satisfied with the overall performance of the system, thus giving an answer to the above-mentioned research objective, and proving our hypothesis ( $\mathrm{H} 1$ : Merging the flipped classroom with immersive 3D VR and AR will improve a student's ability to understand and level of success implicated by the knowledge transfer).

The issues identified in regard to educators are to set up the content and exercises that are provided as part of homework preparation for students. They need careful pedagogical preparation and additional links and resources to embed within it as additional help for learners. Setting up an intelligent exercise for flipped learning class needs a lot of time and experience for instructors. In conclusion, the utilisation of AR for instructive purposes upgrades the students' learning by communicating visual information which increases the level of knowledge transfer. This innovation permits the utilisation of academic methodologies. This methodology has a couple of benefits that as future work can further be explored and improved, like the inclusion of immersive technologies as homework assignments coupled with inquiry and problem-based learning instructions.

\section{Future steps and investigations}

Our next step is to devise several VR/AR applications in education and further compare different approaches and use different methods and VR/AR applications that will be focused in game-based learning, while at the same time realise a comparison and different data analyses measuring the increase in transfer of knowledge and success through grades and achievements in quizzes.

\section{References}

Billingsley, G., Smith, S., Smith, S. \& Meritt, J. (2019). A systematic literature review of using immersive virtual reality technology in teacher education. Journal of Interactive Learning Research, 30(1), 65-90. Retrieved from https://eric.ed.gov/?id=EJ1214948

Bonner, E. \& Reinders, H. (2018). Augmented and virtual reality in the language classroom: practical ideas. Teaching English with Technology, 18(3), 33-53.

Diao, P. H. \& Shih, N. J. (2019). Trends and research issues of augmented reality studies in architectural and civil engineering education. A review of academic journal publications. Applied Sciences, 9(9), 1840. doi:10.3390/app9091840.

Gadelha, R. (2018). Revolutionizing education: the promise of virtual reality. Childhood Education, 94(1), 40-43. doi:10.1080/00094056.2018.1420362.

Gavilanes, W., Abasolo, M. J. \& Cuji, B. (2018). Summary of reviews on augmented reality in education. [Resumen de revision essobre Realidad Aumentadaeneducacion]. Espacios, 39(15).

Godwin-Jones, R. (2016). Augmented reality and language learning: from annotated vocabulary to place-based mobile games. Language Learning and Technology, 20(3), 9-19. Retrieved from http://It.msu.edu/issues/october2016/emerging.pdf 
Ibanez, M. B. \& Delgado-Kloos, C. (2018). Augmented reality for STEM learning: a systematic review. Computers and Education, 123, 109-123. doi:10.1016/j.compedu.2018.05.002.

Jaramillo Henao, A. M., Silva Bolivar, G. J., AdarveGomez, C. A., Velasquez Restrepo, S. M., Paramo Velasquez, C. A. \& Gomez Echeverry, L. L. (2018). Augmented reality applications in education to improve teaching learning processes: a systematic review. [Aplicaciones deRealidadAumentadaeneducacionpara mejorar los procesos de ensenanza- aprendizaje: Una revision sistematica]. Espacios, 39(49).

Lim, S. M., Pang, D., Goei, S. L., Matimba, H. \& Van Joolingen, W. R. (2018). Virtual reality enzymes: an interdisciplinary and international project towards an inquiry-based pedagogy. In Y. Cai, W. R. Van Joolingen \& Z. Walker (Eds.), VR, simulations and serious games for education. Gaming media and social effects. Singapore: Springer. 